\title{
Anxiety and Its Nosographic and Psychopathologic Place in German Psychiatry: A Historical Perspective
}

\author{
Géraud, Marc \\ Centre Hospitalier Charles Perrens
}

France

\section{Introduction}

The Germans use the term "Angst" more often than we do. The preposition which goes with it is "vor" (in front (of)): you can have "Angst vor..." (a storm, certain animals, etc.). It implies some imprecision with regard to the subject; when the subject is specified, the expression is Furcht (fear). It is etymologically derived, in the sense of tightness, oppression, from the Indo-European word group eng. Latin angustus, narrow, angustiae: narrowness, compression, difficulty.

\section{Recognition}

Anxiety was acknowledged only relatively late on; although it is mentioned in one of the first German works on psychiatry, Reil's Rhapsodies, it does not begin to acquire a status more or less independent from melancholia until Krafft-Ebing, where it is linked in such a way as to become visible. The second moment of conception for anxiety disorders was the introduction of the term agoraphobia by Westphal (1872). But the real bombshell was the direct attack by Freud on neurasthenia, which left only a small group of symptoms remaining, opposed to anxiety neurosis, a new, independent entity considered, however, from the outset as often intertwined or associated with the other "important neuroses," hysteria and obsessional neurosis.

\section{Anxiety in limbo}

\subsection{Reil}

In one of the first works in German psychiatry, the Rhapsodien über die Anwendung der psychischen Curmethode auf Geisteszerrütungen (Rhapsodies on the Use of Psychological Therapies for the Mentally Disturbed) (1803) by Johann Christian Reil, the word Angst, along with its derivatives (ängstich, beängstigen), is indeed used, but anxiety is not described as such. The term is very often employed in association with other names for a series of emotions, such as: "It is in our power to produce a great number of illnesses and, through them, pathological feelings of the most diverse type: disgust, itching, tickling, pain, anxiety etc. which, as symptoms of these disorders, are inseparable from them." It can occur 
during the course of an illness: a propos of one woman who had visions: "One day, she was pacing backwards and forwards, in despair, in her room and someone who was trying to stop her placed a hand on one of her eyes by accident. Instantly, all the apparitions disappeared, and with them, her anxiety." Or again: "... If (certain organs) suffer from dynamic or organic illnesses, mood changes without external cause. The patient is dispirited, bad tempered, fixes on things of secondary importance concerning, in particular, his own body, swings between bravery and discouragement, fear and hope. The imagination fixes on obsessions, images of anxiety, and gives birth to the most curious monsters." "An elderly bachelor who had offended another, more courageous, feared his revenge. He left his home and bought a property in the country, several leagues away. But the inner anxiety persisted ..." "Professor Moritz was ill and so full of anxiety because of the uncertainty of his recovery that his fever was continually fuelled." And this wonderful sentence: "Melancholia is an anxiety plunged in a single thought and remains fixed there, with no fever." "In the beginning the fixed delusion is no doubt based on a physical or moral anxiety, which ends up by leading to a total confusion of understanding." These little clinical observations show us clearly that anxiety had been spotted, but that it only ranked as a symptom, certainly not as an illness.

Anxiety is taken into greater consideration in the fourth volume of his work on Fevers (on nervous disorders) (1812). Here we find the series (hunger, thirst, craving, fatigue, distaste, cold and hot, anxiety, etc., p. 49). Certain pathological pictures are observed early on (phobia: "Many people can't stand cats; their presence, even if they can't be seen, causes anxiety and fainting.").

\subsection{Autenrieth}

Ferdinand Autenrieth, who was not a specialist in psychiatry but wrote a text in 1807 concerning the installations he had had put in for the insane in Tübingen (Über die im Clinicum in Tübingen getroffene Einrichtungen für Wahnsinnige), very rarely mentions the word anxiety, whether in Versuche für die praktische Heilkunde aus den clinischen Anstalten von Tübingen (1808), in Über den Menschen und seine Hoffnung einer Fortdauer vom Standpunkte des Naturforschers aus (1825) or in Ansichten über Natur- und Seelenleben (1836). It is always presented in the form of an adjective (ängstlich) in the Versuche, generally in connection with respiration, except in one case where it is a question of a "really debilitating" anxiety (Angst) (Autenrieth, 1808, p. 421). Autenrieth also mentions the anxious movement of the hands and the feet of the newborn ("The infant suffers much during birth, the violent passage into a new world (the second for him); his first act is to cry and anxiously agitate his hands and feet."'Autenrieth, 1836, p. 86). Precognition of birth trauma? Autenrieth treated Hölderlin before placing him by the carpenter Zimmer. His "intern" was Justinus Kerner.

There was more regard for anxiety in the fourth volume of his work on Fevers (on nervous illnesses) (Authenrieth, 1812). Here too there are these series (hunger, thirst, craving, fatigue, disgust, cold and hot,Autenrieth anxiety, etc.). (ibid., p. 49). Some embryonic pathological pictures are noted (phobia: "Many people cannot endure cats; their presence, even if they can't be seen, causes anxiety and fainting fits.").

\subsection{Heinroth}

Heinroth is the dominant personality in psychiatry at the beginning of this century and era. The layout of his treatises is very systemized (it should be noted that the treatise on Seelenstörungen (Heinroth, 1818), psychological disorders, is subtitled: "outlined from a 
rational point of view"): section, chapter, segment, etc., they are cast in a mould. Heinroth describes himself as a doctor: seelischer Artzt, doctor of the soul . For him, psychiatry (Heinroth uses this term), compared to symptomatological psychology, takes the form of anthropology. It seems to be based on a unique ontological assumption: "The mind is like all other phenomena in nature, a force which can be excited by stimuli". This is the reason why it was said that Heinroth was a romantic. Heinroth considered life in moral depravity to be pathogenic. Health is freedom, and reason.

Heinroth's terminology is very idiosyncratic: for him the symptoms of melancholia are Gemütsdepression (depression of affectivity), Insichversunkenheit (being immersed in oneself), Lossgerissenheit (detachment) in relation to the world without replacement by something better. These two elements, putting forward Gemüt (affectivity) and erecting a concept of religious man, seem to us to be characteristic of Heinroth's psychiatry. The name chosen and developed by Heinroth for mental illnesses was Seelenstörung, literally "disorders of the soul." Pathological states appear in all regions of the mind, the common denominator being the stamp of non-freedom, and which, in addition, diverge individually.

The plan of divine creation in man is disrupted through the latter's fault. "Prey to passions, delusions and vice, the creative work of culture is in him often inhibited, interrupted and repressed; and thus, by considering a process of organisation of development towards a perfect life, that is free, we obtain the concept of a disorder of the life of the soul or, more briefly, soul disorder." (1818, p. 34-35).

From this point of view, any state of disease could be called a psychological disorder. It is therefore necessary to define more precisely the concept of mental disorder, as total stagnation, complete stop, inversion of the tendency to self-improvement, self-annihilation, and where these symptoms are the most marked, psychological disorders. And it is these states in which willpower has completely collapsed and in its place there is a total restraint, a total absence of idea, a perfect, persistent, non-freedom which is commonly called disturbance of the mind, obtuseness of intelligence, delusion, mood disorder, mental disorder in general. Not only freedom but the faculty of freedom has collapsed. Following the upsurge of natural necessity, internal and external (these patients) are not even animals directed by a healthy instinct, but machines.

Mental disorders are precisely the interaction between Seelenstimmung (psychological mood) and the stimulus (Reiz). "The mother is the psychological mood; the father is the stimulus." The latter is always evil.

It has to be said that Heinroth does not say much about anxiety, which shows the precariousness of this notion in psychiatric terms. But this negative result does have a positive side to it: Heinroth does not mention anxiety because his work is anthropological: he speaks of man from a holistic or global point of view and not as a series of fragmentary symptoms. We should therefore recognize that man may indeed enter freely into the life of consciousness, but with a freedom already tarnished, so that he brings with him into the world what is called the original sin $(1918,25)$. The following passage: If free self-determination is the root of virtue, of any worthy existence, then this unfortunate dissociation in relation to it is a blasphemy against our expectation of a saintly existence, a veneration of sin; because to be a servant of singular things and beings, that is the sin $(1818,95)$.

\subsection{Ideler}

In Grundriss der Seelenheilkunde (Elements of mental medicine) (1835-38), Ideler chooses the word Furcht as the leader in his series of pathological disorders: Furcht, Angst, Verzweiflung 
(fear, anxiety, despair), sometimes including the word Schreck (terror). Ideler introduces a theory based on the initial concept of reflex, of reaction: "Avoiding an unnecessary danger is a duty." ("Consciousness of an insurmountable danger arouses, through fear, the natural tendency to flee from it, which makes it a necessary affect when faced with the destructive violence of nature."; "In fear, the depressing agent of danger provokes the tendency to escape by flight.")

\section{The premise of a theory for anxiety: March toward of an anxiety disorder}

\subsection{Flemming}

Flemming (1859) showed that psychological doctrine had run out of steam. His aim was to create a "biological psychiatry." Previous science had only led to "a confusion, at which we have only glanced superficially, to make plain the vanity of efforts made to disentangle this mixture of impressions, memories, combinations of past and present, true and false, and to bring to light from this point of view the sterility of psychical symptomatology." It had been established that alongside the normal physiological functioning of mental activities, there are two deviations of this functioning: Error and Delusion. It is not possible to say how these two deviations differ from each other, nor how they are distinguished from the correct path. The difficulty in attributing a symptom to a given faculty or to a given mental element is similar to that of a carpet expert who has to say whether a defect is due to the carpet maker, the shuttle, the spindle or what. Whatever we try to do, there is mixing, vagueness, change everywhere. If we take disorders contemporary with the beginning of mental life, there are two types: either innate, or evolving with growth. In addition there is a much larger group of disorders which attack the already constituted, healthy mind; there are two types: one which resolves once more into a healthy mental life, one which becomes permanent until death. There is a third group: the case of a normal mental life but with certain particularities and striking deviances or coinciding with the nature of the mental disorder which follows: they bear the germ of a mental disorder (Anlage, disposition). Either the disorders are due to intelligence (errors of thought, delusion) and then attack the Gemüt; or the disorders develop the other way round: a clearer and clearer disharmony in the sphere of tangible feeling. There is thus a group of mental disorders which are accompanied by considerable prostration, a lack of courage, anxiety and an immutable concern. Everything that the sick person thinks and imagines is tinged with bleakness, nocturnal; everything that concerns them, concerns them deeply.

Flemming then comes to a symptom which must be placed amongst the most difficult for the patient, and be ranked amongst those which arouse to the highest degree the compassion of the entourage and the interest of the doctor: precordial anxiety. It appears preferably in states of depression, but it can also be added to states of elation. Even this feeling of anxiety is often taken to be a purely mental symptom, i.e. that it was considered to be a simple effect of the delusional idea, which the patient is occupied with. This is totally inaccurate. These delusional ideas, these distorted representations, about which the patient seems to be anxious, are rather as a general rule caused by feelings of anxiety. In other cases, the anxiety becomes associated with delusional ideas and accompanies them - either the patient places them both in relation with each other, side by side, or they survive beside each other without any relation. This relationship may even take place in the complication of precordial anxiety by hallucinations. For the fear and anxiety provoked by and following sensorial illusions must be clearly distinguished from precordial anxiety. In other cases, 
there may even be no distorted idea and yet the patient is affected for weeks and months by a great imprecise anxiety. Another fact shows the close relationship of this pathological manifestation with the essence of psychoses: it is that precordial anxiety is frequently the symptom occuring first of all, and remains that way for a long time. Whereas the patient feels correctly, thinks logically, carries out his duties and professional tasks, he confesses under the oath of secrecy, that he is accompanied by an unnameable anxiety. These disorders often afflict young adolescents and may last months before disappearing. In melancholy, it is the prevalent psychological symptom which, so to speak, carries all the others. Treatment is totally lacking.

\subsection{Griesinger}

Preceded by Jacobi, he was the reformer of a psychiatry in movement: mental disorders were brain disorders. In the field of mental life, Griesinger introduced the notion of psychic pain, likely to present degrees: "but there is in the sensation and the representation of these states a much more general, more vague feeling of discomfort (...) Thus bodily states of general malaise, bodily impediment, etc., with no localized pain, such as in the representation of feelings, for no reason, of oppression, of fear, etc." (Griesinger, 1861, p. 34). "States of psychic pain, anxiety, dread, sadness, chagrin, etc., can be motivated internally or externally, they have for the rest of the body exactly the same consequences as sensitivity to pain. Sleep does not come easily, nutrition suffers, weight loss, and general exhaustion take hold. Psychic pain sometimes alternates with sensory neuralgias." (ibid., p. 37). Anomalies in feelings (Gemüt) can trigger a great number of mental disorders. Feelings of concern are frequent; these feelings of anxiety sometimes reach an unbearable level, a despair that often transforms itself into rage. Anxiety of the soul (Seelenangst) sometimes makes the patient think that he has caused a crime. In melancholia attonita, anxiety is also expressed by physical agitation.

\subsection{Krafft-Ebing's melancholic dysthymia with precordial anxiety}

Certain patients with melancholic dysphoria complained of tormented states of anxiety, felt in the epigastric region, which were associated with distressing feelings of pressure and tightening in the precordial region (Präcordiale Angst, precordial anxiety). These disorders are not given much explanation. Even in physiological life, anxiety is a well known phenomenon. A danger, work where the result is uncertain, produce a distressing affect of expectation which is also associated with anxiety and with troublesome sensations in the epigastric region. What relationship do these precordial sensations have with the conscious state of anxiety that cannot be analyzed in more detail?

- Are they the expression of excitation of sensitive peripheral nerves, where the state of excitation is led right to the seat of consciousness, generates anxiety there, to be felt, projected eccentric in their place of generation? In this case, these paresthetic and paralgic feelings (sensitive nervous excitations, state of excitation sent to the seat of consciousness, generating Angst there, or Lust, projected towards the place of generation) would be the cause of Präcordialangst.

- Or are they, like anxiety, the expression of a central excitation of certain nerve paths serving the transmission of coenesthesic feelings to the peripheral terminal of the transmission channel? In this case, they would be simple co-sensations triggered centrally but felt peripherally, in the field of certain sensitive nerves. 
In these two cases, it is a question of occasioning factors, not of the initial cause of the phenomenon. Precordial anxiety can be found in nicotine poisoning, hydrophobia, epilepsy, hysteria, hypochondria, melancholia, certain neuralgias of internal organs (angina pectoris, cardialgia, colic).

The circumstances in which precordial anxiety is observed are multiple. But precordial anxiety occurs during excitation of a sensitive nerve of internal organs and not in the spine. It is observed at best in angina pectoris. Even the vague nature, which does not permit location, is in favour of its formation in sensitive paths in internal organs.

Everything seems to indicate that the place where precordial anxiety arises is probably the cardiac plexus. Its constant location in the heart region, the fact that it generally appears in neuroses of the cardiac plexus nervosus (angina pectoris), that it is preferentially caused by nicotine, that other disorders occur at the same time as precordial anxiety (palpitations, disorders in regularity of heart beat, anomalies of pulse, etc.). all this indicated that the peripheral cause of precordial anxiety should be sought in the cardiac plexus nervosus. This nerve plexus consists of 1 ) the stimulating nerve fibres of the sympathetic, 2) the inhibiting nerve fibres of the vagus, 3 ) the autonomic cardiac nervous system. What one can suppose is that Präcordialsangst is probably a vasomotor neurosis of the heart. Angina pectoris, or eventually precordial anxiety, may be the expression of a vascular constriction striking the arterial vessels of the heart. However, in certain cases of stenocardia, there are no anatomical discoveries: these could be nervous forms.

The dependence of anxiety on these mental excitations can be easily explained. It is triggered by:

1. Mental stimuli (representations and frightening apperceptions, affects) conveyed through the paths of the vagus or the sympathetic towards the cardiac plexus. Predisposition consists in the increase of excitability and the lability of equilibrium (hysteria, epilepsy, melancholia, etc.).

2. By irradiation of internal organ neuralgia (cardialgia, colic) on the cardiac nervous system by sympathetic paths, which would explain the frequency of precordial anxiety during these neuralgia of internal organs.

So, precordial anxiety appears when a stimulus-representation, or the transfer of a state of excitation in the nervous paths of internal organs (sympathetic), place the vasomotor nerves of the heart muscle in a state of high excitation, which causes a vascular constriction in the heart muscle. The thus disrupted function of the autonomic ganglions of the heart muscle is transmitted to the seat of consciousness and causes the feeling of anxiety which is projected eccentric on the site of its origin.

Frequently these feelings of precordial anxiety are added to the pathological picture of melancholia sine delirio: it is a complication (melancholia epigastrica, dysthymia epigastrica).

This additional content of distressing consciousness has a much deeper significance because of the feelings of anxiety of the other mental functions. The depressive mood increases with anxiety and results in the affect of Verzweiflung (despair), which is also expressed by mimics and gesticulations. Apperception lead to a complete mental anaesthesia dolorosa, consciousness suffering from emptiness and desertification, because faced with this powerful internal state, external stimuli are no longer taken into account which often leads to temporary suppression of apperception and to the obscure representation of universal non-existence. The Vorstellen (ideation) sustains feedback because of the confusion in the unfolding of the course of representations, which is completely suspended and where the indeterminate confused representation of anxiety constitutes the content of consciousness, or by the filling of the representational field of a confused disorder of representations which 
are no longer dominated and no longer able to be associated and leads necessarily to confusion. At the highest point of the anxiety attack, there can even be momentary suspension of self-awareness. Anxiety always has effects on the motor response (importance in medico-legal psychiatry).

The motor agitation intended to resolve the mental tension may result, to a certain degree, in murder and suicide, in fires, destruction of everything which stands in the way of the patient. Analgesia which condition is mental and which belong to the upper degrees of anxiety attacks leads to the most appalling self-mutilation. In rare cases, precordial anxiety occurs as psychoneurosis (sic) fully acute, transitory, independent, elementary (Raptus melancholicus).

The course of melancholia with precordial anxiety is chronic or subacute. Prognosis is reasonably favourable.

\section{The first anxiety disorder: Westphal's agoraphobia}

Carl Westphal begins by remarking that for a number of years, repetitively, patients came to him with one particular complaint: that it was not possible for them to venture into open places or into certain streets, and that the fear inspired by these journeys hindered them in their freedom of movement. The patients were afraid that they would be made fun of, or that they would be considered to be mad. "This fear of crossing open spaces or eventually of going into streets represented the main phenomenon so clearly that, although it was related to some other situations and that the designation chosen - for I thought it necessary to do so - is not completely exhaustive, I believed I should construct the word agoraphobia (agora), fear of open spaces." (Westphal, 1872, p. 138)

It is impossible for the patient to walk in empty open places. If he tries to do so, he is immediately overcome by a feeling of anxiety, and when questioned, he situates this feeling more in the head than in the region of the heart, even though he often has palpitations. The feeling appears when he obliged to walk alongside a wall and alongside buildings or to go into streets when the shops are shut. To protect himself, he will follow a passer-by or walk with a demi-mondaine, or look for the red lanterns of cabarets.

In all these cases, the feeling of anxiety is perfectly unmotivated, the patient does not know why he is different from other men, and even "he cannot understand how others can walk across an open space." He has no idea what anxiety is, it is, so to speak, Angst vor der Angst (fear of fear itself) 'ibid.,p. 141.

At the history taking interview, the patient says he has Flimmern (flicker of light, luminous curtain) before his eyes.

From observation of his patients Westphal draws the following principles:

- The patients can find no reason for the anxiety which assails them.

- As if it were an integral element of the feeling of anxiety in the registers of the representation, the idea comes to the patient that he cannot cross the open space and he represents to himself (perceives ?) that it is monstrously large.

- Secondary idea that something might happen to them.

- The patient can only indicate the external circumstances in which this state occurs, and can say no more, apart from that the anxiety and the thought are suddenly there, psychologically perfectly unmotivated.

- The external circumstances are the same: the emptier the open space, the easier it is for the state to occur; even hugging the façades, sometimes just the simple fact of passing in uninhabited or empty streets, at worst just going a short distance along a known route, has the same effect. 
- The state is eased or even disappears when there is an escort, when a carriage goes by, when the patient sees an open door in one of the houses in an empty street. But the ingestion of alcohol, by the excitation it causes, enables the patient to overcome the state.

- This state differs from the Schwindel (vertigo) of Benedict and Griesinger: "Right from the outset is it not vertigo, but a feeling of anxiety."

- It is manifestly cerebral (in the mind) and has little analogy with the normal psychological processes, it is also just as impossible to be understood by them, as with other pathological states, affects, directions of representations and wilful impulses.

- Appearance of the affect (fear, anxiety) under certain circumstances and conditions, disappearance when these are removed.

- The patients are not "mad."

- The absence of any resemblance to mental illnesses means it should be called "neuropathic." The name "mental illness" is not justified.

\section{Definition of anxiety disorder: Freud's anxiety neurosis}

In 1894, in an article entitled 'On the Grounds for Detaching a Particular Syndrome from Neurasthenia under the Name "anxiety neurosis" ' Freud proposes to separate from neurasthenia neurotic syndromes more solidly related to each other than to the typical neurasthenic symptoms (pressure in the head; spinal irritation; dyspepsia with flatulence and constipation) and differing in their aetiological mechanism. The pseudoneurasthenias (nasal reflex neurosis, nervous symptoms of cachexia and of arteriosclerosis, preliminary stages of progressive paralysis and numerous psychoses), are finally separated from neurasthenia, as well as some status nervosi of hereditary degeneration, and the many neuroses of an intermittent nature which have to be classified in melancholia. It remains a complex whose symptoms are very close to each other (often appearing together or replacing each other) and whose aetiology and mechanism are fundamentally different from neurasthenia.

It is called Angstneurose (anxiety neurosis) because all the elements are grouped around the cardinal symptom of anxiety for each is connected with anxiety. Freud mentions Hecker ${ }^{1}$ at the beginning of his article.

\subsection{Clinical symptomatology of anxiety neurosis}

It sometimes constitutes a gemischte Neurose (mixed neurosis with complex symptomatology). The clinical picture is as follows:

\subsubsection{General excitability}

As is, this is common to several neuroses. It is constant, corresponding to an accumulation of absolute or relative stimuli. There is an auditory hyperesthesia. It is often the cause of insomnia.

1 Hecker, 1893 « Über larvierte und abortive Angstzustände bei Neurasthenie ». For Hecker, more than half of neurasthenics have anxiety states. But Hecker emphasized a surprising fact, that is that the nature of the feeling which dominates the patient does not always come into consciousness as anxiety (larvierte Angst = masked anxiety ), but is interpreted otherwise by them until someone enlightens them. In addition, it is sometimes one or other of the corporal markers of anxiety which occurs in very isolated and marked fashion: abortive or incomplete access. 


\subsubsection{Anxious expectation.}

This includes "anxiety and pessimism." It often takes the form of a compulsion. When it concerns health, it leads to hypochondria (it then requires the presence, in addition, of paresthesias and distressing bodily sensations). In the most morally sensitive, it is expressed by Gewissenangst (anxiety of moral conscience), scrupulousness and meticulousness, which can even turn to Zweifelsucht ("folie du doute", doubting mania). It is the core symptom of neurosis. There is a freely floating quantum of anxiety, which dominates while awaiting the choice of representations and it is always ready to associate itself with a representation.

\subsubsection{Anxiety attack}

This is not the only way for anxiety, generally latent to consciousness but constantly on the watch, to express itself. Its sudden penetration into consciousness is the anxiety attack. Either the anxiety is by itself, or it is accompanied by a representation (annihilation, fit, threat of madness), or disorders of other functions (heart attack, respiratory distress, sweating, craving) and, in the words of the patient, anxiety remains hidden behind, or can only be described as "feeling faint" " feeling discomfort," etc.

\subsubsection{Rudimentary anxiety attack and equivalents}

- Disorders of cardiac activity (palpitations, etc.)

- Respiratory disorders

- $\quad$ Sweating

- Attacks of trembling and shaking

- Attacks of craving

- Acute diarrhoea

- Locomotor vertigo attacks

- Congestion attacks

- Paresthetic attacks

\subsubsection{Pavor nocturnus}

Variation on anxiety attack: frightened awakening at night, often with dread, dyspnea, sweating; it leads to a second form of insomnia.

\subsubsection{Anxiety and vertigo}

Schwindel (vertigo) differs from anxiety.

\subsubsection{Phobias}

Based on chronic Ängstlichkeit (anxiety) (anxious expectation) and a tendency to anxiety vertigo attacks, two typical groups of phobias develop:

- Anxiety in the face of universal physiological threat: snakes, storms, darkness, vermin, typical moral hyper probity (Zweifelsucht, doubting mania); the anxiety available is only used to reinforce instinctive repugnance. A compulsive phobia is generally only formed when there is a reminiscence during which anxiety was expressed. These events only remain intense in those with anxious expectations (ängstliche Erwartung) (these cases should not be explained by the persistence of strong impressions).

- The other group is that of locomotion which includes agoraphobia and all its variations. It is often preceded by a vertigo attack, but this is not an obligatory postulate. 
The connection between these phobias and the phobias of obsessional neurosis is as follows: the displacement applies to both types of phobia (a representation becomes obsessional by connection with an available affect). But in the phobias of anxiety neurosis: 1) The affect is monotonous anxiety) but, 2) there is no substitution (it does not come from a repressed representation, it is invincible). But the substitution can be secondary, takes hold of protective measures: rumination for example, which initially serves to combat doubts concerning the faculty of reasonable thought. Doubting mania and other manifestations belong to anxiety neurosis.

\subsubsection{Digestive activity}

There is a few symptoms but they are characteristic. Nausea, craving, tendency to diarrhoea.

\subsubsection{Sensitivity disorder}

Paresthesias; increase in sensitivity to pain, tendency to hallucinations that cannot be interpreted as hysteria.

\subsubsection{Chronicity}

The symptoms which accompany anxiety attacks or its replacement also appear to be chronic.

\subsection{Appearance and aetiology of anxiety neurosis.}

There is often no recognized aetiology.

If the neurosis is acquired, there are a series of troubles and influence in sexual life that a careful, controlled examination will reveal.

\subsubsection{In women}

a. Virginal anxiety, anxiety of adolescents: first encounter with a sexual problem, such as a sudden disclosure of that which was previously hidden. It is typically combined with hysteria.

b. Anxiety of young brides.

c. Anxiety of women whose husband suffers from premature ejaculation or

d. Who practice coitus interruptus or reservatus.

e. Anxiety of widows and intentional practitioners of abstinence. This is often accompanied by an obsessional neurosis.

f. Climacteric/menopausal anxiety

\subsubsection{In men}

a. Abstinence, often with symptoms of defence (obsessional representation, hysteria).

b. Frustrane Erregung (frustrated excitation) (case of persons who are satisfied with touching)

c. Coitus interruptus,

d. In the Senium (old age):

$\alpha$ Neurasthenics following masturbation who fall into anxiety neurosis in the case of abstinence: they have become unable to tolerate abstinence.

$\beta$ Overwork. 


\subsection{Outline of a theory of anxiety neurosis}

- It must be an accumulation of excitation which does not allow a psychical derivation of anxiety.

- There is no trauma (which would lead to hysteria or accident neurosis).

- In certain cases, there is a decrease in sexual libido, of psychical pleasure.

Therefore: the mechanism of anxiety neurosis must be sought in the derivation of sexual excitation from the somatic to the mental and the abnormal use thus caused by this excitation.

The physiological functioning is the accumulation of somatic sexual excitation; at a certain level of accumulation, it becomes a Reiz (stimulus) for mental life, resulting in a psychic state of libidinal tension.

Discharge is only possible thanks to adequate, specific action.

When the action of discharge is not a specific action (masturbation) neurasthenia appears.

All the factors which prevent the psychic elaboration of somatic excitation lead to anxiety neurosis.

Example of a voluntary abstinent. Abstinence consists of the privation of the specific action, which otherwise follows the libido. This privation will have two consequences: accumulation of somatic excitation and dispatch towards routes where discharge is more possible than on the psychic route. Libido will end up by decreasing and the excitation will be expressed subcortically in the form of anxiety. Abstinence is also an effective element in the aetiological group of frustrated abstinence. In the case of coitus reservatus without consideration, libido disappears progressively, what follows is equal to the case of abstinence. In senium, there is such an increase in the production of somatic excitation that the psyche is relatively inadequate to control it.

In women, in the case of virginal anxiety, the representational groups to which somatic sexual excitation must be linked are not sufficiently developed. In the anaesthetic bride, anxiety only occurs when the first periods of cohabitation arouse a sufficient quantity of somatic excitation; where the local symptoms are lacking, anxiety does not appear. The case of premature ejaculation, of coitus interruptus has the same explanation as in men: libido disappears psychically for the act while the excitation aroused is discharged at the subcortical level. The case of widowhood and of intentional abstinence as well as that of the climacteric/menopause is resolved as for men.

Anxiety neurosis is therefore a neurosis which certainly does not have a sexual aetiology, but does have a sexual mechanism.

The symptoms are, so to speak, a surrogate for specific action.

Why does psychic failure to control sexual excitation lead to a neurosis? "The mind provides an affect of anxiety when it feels incapable of settling a task coming from outside (danger) by a corresponding reaction"; it arrives at anxiety neurosis when it sees it is incapable of counterbalancing the (sexual) excitation produced endogenously. It behaves as if it projected this excitation towards the exterior. The affect is a reaction to an exogenous excitation, neurosis to a similar endogenous reaction. The affect is a state which passes quickly (sudden); a neurosis is chronic (persistent). In neurosis, the nervous system reacts against an internal source of excitation, whereas the affect corresponds to the reaction against a similar external source.

\subsection{Connection with other neuroses}

Where a mixed neurosis exists, evidence can be found of a combination of several specific aetiologies. Comorbidity may be fortuitous, or indicate an even closer connection between symptoms since the same aetiological condition will regularly and simultaneously cause both neuroses. 


\section{Loewenstein}

Loewenstein wrote a large volume on obsessional disorders in which there are some interesting notes concerning anxiety. He thus defines the anxiety state: "We call feelings of anxiety the specific emotional elements having a harmful significance for our person or for any person belonging to our sphere of interest which are attached to an imminent event or to one that has already occurred." The feeling of anxiety (Angstgefühl) corresponds to a psychological state characterised by the presence of feelings of anxiety, by an affect of anxiety, an anxious state in which the most intense feelings of anxiety are contained.

The pathological nature resides in the compulsive aspect, unable to be influenced by counter-representations; the phobias are insensitive to logical considerations and unable to be influenced by willpower.

\subsection{Symptomatology of the state of anxiety}

Loewenstein meticulously studied the psychic and somatic symptomatology of states of anxiety that we cannot detail for lack of space.

His analysis of any affect of anxiety arising from a representation shows that feelings of anxiety are a sort of feeling of displeasure which has no demonstrated location and should be considered to be a subjective accompanying manifestation of a general cortical state. We don't know where anxiety gets its special hue from. "Alongside cortical primary anxiety, a bulbar anxiety can be distinguished." (p. 316). Bulbar anxiety is distinguished by its disproportion; minimum stimulus, with disproportionate symptomatology. There are often inaugural organic symptoms. (Auras)

\subsubsection{Abnormal predisposition to anxiety}

Ängstlichkeit: abnormally increased tendency to anxious states, which appear on occasions that would cause no anxiety for the average person, and, on occasions that give rise to a trite fear, they react with an anxiety with extraordinary intensity. According to Freud, ängstliche Erwartung is the core symptom of anxiety neurosis. It may occur in a normal personality under harmful influence, weakening the nerves, but in general it is innate or inherited, developed and completed by toxic influences. It runs from pessimism or timorous tendencies through a series of nuances up to constant, irrational expectation of the worst misfortunes (Beard's pantophobia). General anxiety: fear at the slightest possibility of a drawback.

- Hypochondriac anxiety, in particular with regard to the state of health. It is innate or acquired.

- Moral anxiety seizing the slightest moral or religious scruple. A subspecies is the fear with regard to maintaining good manners in the world. Immense fear of a breach of courtesy or of morality leading to pedantry (exaggerated precision).

- Abnormal anxiety with regard to the state of health of relatives.

- Abnormal anxiety with regard to one's fortune and professional affairs. Schwarzseher (those who see everything on the black side), pessimists.

With regard to the organic foundation of abnormal predisposition to anxiety, one should first of all mention hyperexcitability of the cardiovascular system, innate or acquired. This means that emotional processes of a distressing nature and leading to a circulatory influence give rise to organic feelings which are attached preferably to representations of misfortune 
(Erwartungen, expectations). Neurasthenia (lowering of performance of the nervous system) also encourages the development of an anxious disposition because it diminishes selfconfidence and snatches from consciousness the ability to avoid certain dangers or to overcome them.

\subsubsection{Simple anxious states, without content}

They do not proceed from the representation of a danger. Their duration is variable (from one minute to several months). They are variable in intensity. Very frequently tied in secondarily to representations of a threatening danger explaining the anxiety.

Frequency varies a lot.

They are frequently incorrectly interpreted or designated: nervousness, excitation. Choice of an accompanying bodily manifestation (heart palpitations).

\subsubsection{Chronic anxious states}

These differ from the preceding not only in time, but also in the intensity of feelings of anxiety and in the influence thus produced on the general psychological state. Here it is not a question of duration of attack, but a remittent behaviour, sometimes even sporadic. Sometimes, the states of anxiety are reduced to a minimum for more or less limited periods of time and sometimes they disappear completely. By durable states of anxiety we mean those for whom, for a fairly long period of time, there are daily anxiety attacks and in general the free intervals give way to intervals more or less occupied by anxiety. Their intensity is low to moderate. There are sometimes developments of more intense anxiety, completely excessive.

\subsection{Phobias}

These are anxious states with particular triggering factors, or at least originating from certain representations. Some authors place them in the category of obsessional neuroses; they have been separated from the latter by Thomsen, Krafft-Ebing (changing opinion).

In fact, phobias are complex processes. There are three types of phobias:

- Phobias with constant representational content. The representation to which the anxiety becomes attached, the object of the fear, is that which occurs primarily in nature, it is a type of Zwang (compulsion), and has a well determined content (nosophobia, contact phobia, mysophobia, zoophobia, active and passive kleptomania).

- Phobias with floating representational content. The typical example is agoraphobia or Platzangst (fear of open spaces). These phobias change between individuals and even in the same individual (falling, vertigo, collapse, accident involving heart or brain, strange apparition or something quite indefinable, bad).

The anxious state is the constant, prevalent factor here, whereas the related representations change. It differs in several phobias. Secondarily, obsessions can become intertwined between phobia and anxious state.

- In a third group of phobias, anxiety becomes attached to certain representations which do not have the character of obsession because it is simply perceptions that are involved; anxiety here is not conditioned by the content of problematical representations either, but is in fact empty. Certain zoophobias, fear of insects (spiders, cockroaches) of mice, necrophobias: the affected person does not know what it is they 
are frightened of. Pathological increase in certain aversions situated in the realm of the psychological.

Only the first type of phobia can be classified in the obsessions.

\subsubsection{Phobias with floating representational content (p. 332)}

There are a large number of triggering factors. The characteristic of them all is that they offer no reason to be afraid, at least for the index cases, and that the patient knows it but cannot refrain from being subjected to it. There is no predisposition. They develop all by themselves in anxious, hesitant natures but many do not appear in those with anxiety disorders.

- Phobias of locomotion: a state of anxiety relating to locomotive acts, such as in agoraphobia. There are several degrees and nuances.

- The more mild cases: occur often in the middle of the journey, in the form of discomfort or of an anxiety which makes continuation difficult, but not impossible, all the more so if the patient is following a person or a car.

- Intermediate cases, crossing open spaces is impossible; great difficulty in crossing bridges and main road junctions.

- The most serious cases: the patient can only go out into the street accompanied by another adult.

These nuances can be seen with the same patient.

- Phobias of situation: agoraphobia is only one type of obsessional representation that can be called topophobia. It is often accompanied by claustrophobia. The patient is not very clear about the nature of the disorder. Attacks can be repeated (theatre, Church) leading to Zwangsbefürchtungen (obsessional fears) that these will be repeated in the same place, or by a malaise that will encourage them to leave, or the obsessional idea that is impossible to remain. 1) Either the patients continue to frequent the places in question, taking a seat near to the exit or go with an escort. Or 2) they abandon the idea of going out - claustrophobia. Anthropophobia - the simple fact of being with another person, in some cases, can cause states of anxiety. In more mild cases, there is a certain aversion in relation to society (for there is a risk of discomfort, embarrassment). In the most serious cases, relationships with people are always accompanied by anxiety attacks, which drives the patient to abandon their work and give up all dealings with other human beings. Gynecophobia can occur in male neurasthenics with sexual hyperesthesia. Basically it is a fear of sexual excitation, caused by the sexual act or upon the sight of women. The fear of women amounts to the fear that they may cause states of anxiety (phobophobia). Solitude can trigger states of anxiety.

\subsubsection{Functional phobias}

These are anxiety states occuring during professional activity (previously carried out with no emotional excitation), following fortuitous circumstances. First of all, these anxiety attacks need to have developed during the work activity in question or when a disorder reoccurs in the given field,to the extent that itmore or less with its accomplishment. The patient develops the obsessional idea that during their work, the anxiety attack or a related disorder might reoccur, or that the level of performance required is impossible for them. Some continue the action, others do not. The energy of willpower, the pressure of external circumstances, the need to earn money, all play a very important role along with the 
intensity of the attack. Attacks occur in the clergy, more rarely in teachers, lawyers while pleading at the bar, musicians and singers. There are traumatic phobias so intense that the patient has to give up work. For topophobes, anxiety attacks can occur on a train or tram. An escort is necessary. Fear of heights (hypsophobia), vertigo.

\subsubsection{Anxiety phobia without content}

Necrophobia, morbid fear of blood, (haemophobia), fear of storms (astrophobia).

The triggering factors are very variable.

There are 4 types of case:

1. Sudden and spontaneous appearance, for example when crossing a bridge, of an intense anxiety with its somatic consequences. It can be without content or drag along with it the representation of a possible danger or accident if the same situation is maintained or continued.

2. Physical malaise, nausea, weakness and dizziness awaken the representation of helplessness in an accident, the possibility of a fall, of not being able to continue, or of arousing curiosity, where its representations are mixed with more or less intense feelings of anxiety.

3. In the rarest cases and in individuals who are anxious, there appears a representation of the possibility of an attack accompanied by helplessness, and this representation is associated with corresponding feelings of anxiety.

4. A first attack following a fright (accidents) (traumatic phobia). The same effect in the street or in public places with the appearance of serious medical conditions, in particular epileptic. The phobia can then develop after eviction of the stimulus.

\subsection{Latent and incomplete attacks of anxiety (equivalent of anxiety attack)}

Hecker drew attention to anxiety attacks without anxiety: masked, incomplete or abortive. For Freud (Über die Berechtigung...): any accompanying symptom can constitute the attack, such as anxiety.

There are three types of masked attacks:

a. Anxiety replaced by one of its preliminary stages (emotional elements).

b. Erroneous interpretation of anxiety as being a change in psychological state (Verstimmung, etc.)

c. Anxiety interpreted as being a purely physical disorder (asthma, nausea, palpitations, craving, etc.). In this case diagnosis is difficult. Attacks of dizziness in cerebrasthenics only became associated with feelings of anxiety later on. For Freud, dizziness differs from vertigo (Drehschwindel) and from Ménières disease.

\subsection{Aetiology}

The data indicates that anxiety affects men twice as much as women (2 to 1$)$. The most affected being those between the ages of 30 and 40 years. It is rare in children but there are adults who have suffered since childhood. It is certain that hereditary is involved in $80 \%$ of cases. There is little connection between content and intensity. Sometimes there is a hereditary content with little or no neuropathic predisposition: there is a special predisposition to anxiety disorders. There is an influential sexual aetiology before the start in only $75 \%$ of cases (all disorders considered). There is no specific factor there. The importance varies greatly in individual cases. Do not support Freud's theory: 1) cases 
without accumulation of somatic sexual excitation. 2) cases with accumulation, but lack of mental derivation. For Freud the symptom is abstinence or the disappearance of libido. In the case of Loewenstein with sexual abstinence, libido was as often increased as reduced. Sexual aetiology lacks in some cases such as phobias: agoraphobia with anxiety attacks.

The merit of Freud is in having drawn attention to the importance of toxic sexual agents in the origin of anxiety states. Mechanism: toxic chemical cause, nervous cause; nervous exhaustion. (Loewenstein, 1904, p. 473) "As we have seen, toxic sexual agents figure relatively rarely as the exclusive source in anxiety states." (ibid.) Phobia anxiety is habitual. It is triggered by psychical processes, in part subconscious. The subconscious processes often come from anxiety states with no content and masked.

Conclusion: 1) the hereditary component is most certainly not constant, but in a great majority of cases it operates in adults, although only rarely as exclusive cause; its role is restricted to raising the pathogenic action of other causal factors = main causes. 2) The main causes are etiological factors which are generally necessary to induce an anxiety state, and sometimes sufficient when they are fairly intense, we have met a series of somatic and mental disorders. Somatic: sexuality; mental: emotional toxicity. No specific cause, i.e. equal and constant etiological factor in all cases. In addition, we have found: 3) subordinate causes and 4) triggering factors.

\section{Kraepelin}

\subsection{Anxiety as a morbid disposition}

When the pathological emphasis of displeasure is accompanied by feelings of inner tension, the mental state is stamped with the seal of anxiety (Ängstlichkeit) (vol. I, p. 344) source of obsessional representations, phobias (Zwangsbefürchtungen) and expectation neurosis.

"The form broadly the most frequent of disagreeable pathological emotions is anxiety, that we can perhaps consider as an association of displeasure with inner tension. It is generally without object. It occurs in general by attacks, the most frequently in depressive states of circular madness." (I, p. 348).

"A clinical group of particular anxiety states, very extensive, is finally made up of disorders that it is customary to call Zwangsbefürchtungen (obsessive fears) or phobias. There are phobias of situation, and phobias of function." (p. 350). Particularly frequent is the fear of introducing needles or splinters of glass into food and to thus kill others. The thought of seeing the gaze of strangers directed towards oneself produces when there is a pathological predisposition a distressing feelings: this is the phobia of the stare." The best known example of phobia is Platzangst, or agoraphobia, the feeling of inability to walk in an empty open space, in a deserted street. With cathisophobia, the affected person is afraid of remaining still. Very often, progressively, it is not the original occasion for anxiety that the person dreads, but the anxious tension itself; there then develops an Angst vor der Angst, a fear of fear itself, or phobophobia. (355) Displeasure can be accompanied by inhibition or excitation (attack or transitional state).

We will first of all look at disorders arising from activity and related to it; since these are a question of very mild disorder, I will call them activity neurosis (ponopathies). They contain nervous exhaustion, acquired neurasthenia, which is formed from a durable tension, exaggerated, of a willingness to work. Attached to this is expectation neurosis, anxious discomfort of simple gestures through sombre memories of previous disorders. 


\subsection{Expectation neurosis}

Expectation neurosis (Kraepelin, p. 1416) includes nervous disorders which develop on the common basis of anxiety expectation. Definition: "By expectation neurosis, I would place here a group of nervous disorders which develop on the common basis of anxiety expectation." Through healthy experience, we know that the expectation of any event gives rise to a progressively rising internal tension. If the imminent event is disagreeable, initial feelings can be extremely distressing and even painful. At the same time, the assurance of action is affected very noticeably.

Expectation neurosis offers a similar image, except that it is pathologically increased and coloured. The pathological development is brought about here because the distressing disorders do not occur on a single unique occasion, but follow processes which are unceasingly repeated every day. They do not take place in the usual manner, freely, but are uneasy and distorted by the interference of dysesthesias, feelings of displeasure and impulse unrelated to the goal. As these difficulties are repeated unceasingly and, in the processes influenced by it, expectation anxiety becomes more and more intense and thus reinforces the disorders.

The processes concerned are: (p. 1416-17) processes which in the healthy person occur with no particular intervention of a conscious mental activity, but occur fairly mechanically: walking, standing up, swallowing, falling asleep, reading, writing, speaking, micturition, sexual act, along with abilities such as the playing of the violin or the piano. As Möbius puts it, the disorder is conditioned by the memory of illnesses. (1417)

\subsection{Symbantopathies}

With blows of fate (ta symbanta) situation psychoses, or fate psychoses (symbantopathy) can appear. Terror neurosis and accident neurosis should be mentioned here.

Traumatic neurosis was defined in 1889 by Oppenheim. The main causes are in the region of the emotions. The role of legislation on accidents in 1884 was accused of generating and maintaining this battle for compensation. When injury and traumatic hysteria are eliminated, two scenarios remain: Schreckneurose (terror neurosis) and Rentenkämpfer (who seek compensation).

- For the first group, the designation "terror neurosis" seems the most appropriate because in these cases of terror, a misfortune which suddenly surfaces is the true pathological cause. It presents itself to us as an increase and pathological persistence of the effects that a violent emotional shock exerts on the mental and physical behaviour of humans. In essence, a rapidly installed disorder of consciousness is observed with general excitation of willpower, more rarely inhibition of willpower. The symptoms are those of confusion with impulsive excitation. The cause triggering terror neurosis is constituted by all the events producing violent emotional shocks whether there is physical injury or not. Anxiety also plays a role in the face of a grave danger, and the despair caused by personal misfortune and the misfortune of others.

- Traumatic neurosis (ibid., p. 1457): depressive or sulking dysthymia with moaning, lack of will power/difficulty making decisions and all kinds of symptoms in part generally nervous, in part local. The disorder only develops after a period of time. Months sometimes pass before the disorder is manifest. Patients sometimes go back to work but they have to abandon it again after a more or less lengthy period. Patient symptoms are 
as follows: abnormal apprehension, dysaesthesia, mnemic disorders, mood generally dejected, whining, anxious; they have a "melancholic outlook." Very often they are emotional and sensitive. But what is at the centre of this picture is the inability to work. The tests show a susceptibility to fatigue.

\subsection{Obsessional neurosis}

"Faced with all these somewhat impersonal forms of compulsive thought, there is the bulk of observations where it is immediately a question of the relationship of the patient to life and to their entourage. We can group them under the general name of Zwangsbefürchtungen or phobias." (p. 1882)

The true obsession (impersonal) (p. 1832) is Zwangsbefürchtung (obsessive fear) or pathological fear. (p. 1840). Phobias are divided into: 1) Unglücksangst (vicissitude anxiety) or symbantopathies or symbantopathy; 2) anxiety of responsibility; 3) relational anxiety or homilophobias (phobia of contact with other human beings). The general disorder which is the basis of all declared obsessional processes is anxiety (p. 1863). "I believe that obsessional representations only become pathological manifestations and therefore symptoms of obsessional neurosis when they have become an integral part of Zwangtsbefürchtung, when the anxiety that they might return takes hold." (p. 1865). Obsessional neurosis is not a disorder of representation but of Gemütsleben (emotional life). But the causes of neurosis should be sought in the abnormal psychological constitution (p. 1881). This is what Kraepelin says of Freud: völlig wilkürliche Annahme (perfectly arbitrary assumption) (p. 1883-84).

\section{Conclusion}

"Ihr habt Angst in der Welt," says John, 16,33 in the Bible in Luther's translation. Anxiety is one of the most awful companions that there are. It seems to belong more to the realm of good luck and bad luck than of illness. We have seen that the psychiatrists all mention it, more or less, without giving it any real status, without making it an illness, the core of a given illness, or even a symptom: it is an emotion, "Gemüthsbewegung." It is sometimes even considered to be a causal factor (pathogenic effect of affects). In short, it is not given any particular pathological or nosological importance. We have seen that it begins to assert itself as part of dysthymia with precordial anxiety (Präkordialangst), the authors seem divided between a number of solutions: turn it into an illness, a complication or a symptom. The first to define what is today called an anxiety disorder, Westphal, gives an admirable description of agoraphobia. It should be noted that it is the possibility of access to psychiatrists, for non severe patients who remain in the community, that enabled the description of "neurotic" disorders" (Westphal also provides the fullest description of obsessional representation). To a certain degree it is the structure of health care facilities (relative relationships between health care facilities and residential care facilities, consultations for outpatients, polyclinics), which has enabled this advance in diagnostics. But anxiety bursts into the open with Freud. In his 23rd conference, Wernicke did indeed describe a psychosis of anxiety, but it does not seem to have left any trace, notably because of its close proximity to anxiety neurosis and delusional depression, and the off-putting effect of Wernicke's idiosyncratic terminology. We have also seen that with German authors, the separation between anxiety, phobia and obsession is not very marked: phobia and obsessions are practically intermingled and anxiety is common to all of them; Freud's anxiety neurosis involves phobias. However, 
anxiety states are mentioned in Loewenstein's book on obsessional neurosis. What perspectives are open to this history which we have volontarily restricted to the 19th century? In the evening of his life, Freud takes up the problem of anxiety again and resuscitates at the same time the old term Abwehr (psychoneuroses of defence). Anxiety becomes Realangst, anxiety in the face of something real. It is a signal of the appearance of a danger. It is the archaic precipitate, Erinnerunsgsymbol (mnesic symbol) of a great trauma: the trauma of birth. Anxiety is no longer libido transformed, but a signal of the occurrence of a danger. Freudian theory becomes more and more complex; it will develop towards a study of the mechanisms of defence of the ego against anxiety, whereas originally with Freud they are a defence against drive. Another path is opened up, blazed in Germany mainly by a brilliant author, Viktor Emil Freiherr von Gebsattel. The vocabulary and discriminations of the established authors are smashed to pieces. Gebsattel's texts are extremely complex, it is impossible to summarize them. Let us say that Gebsattel moves away from the proliferation of anxiety (Gebsattel worked in consulting rooms for a long time and therefore with neuroses, terminology which he retains). He attributes it to a nihilistic tendency of society. For existential philosophy, which inspired Gebsattel, anxiety is "the fundamental position which places [one] before nothingness" (Heidegger). This theory is that "anxiety manifests nothingness." The nothingness that man meets with in anxiety is his own nothingness. In the Psychopathology of Phobia, he emphasizes the aspect of psychoasthenic weakness that through its hanging back prevents man from coming to grips with a world which fills him with anxiety. Gebsattel talks of Aufdringlichkeit des Angsphänomens (irruptivity and extension of the anxiety phenomenon). The extent of the "phenomenon" is measured, for example, in the quantity of psychotropic drugs taken. We have not mentioned here the differences between neurotic and psychotic anxiety (these two nosological vehicles which collapse), nor the "content" of the anxiety (death, castration, solitude, fragmentation) which exceeds our strictly clinical framework. Between anthropology, nothingness and synapse, anxiety is still searching for its place.

\section{References}

Autenrieth JCF (1807) Über die im Clinicum in Tübingen getroffene Einrichtungen für Wahnsinnige.

Autenrieth, JCF. (1808) Versuche für die praktische Heilkunde aus den clinischen Anstalten von Tübingen.

Autenrieth, JCF. (1825) Über den Menschen und seine Hoffnung einer Fortdauer vom Standpunkte des Naturforschers aus (Cotta) Tübingen

Autenrieth, JCF. (1836) Ansichten über Natur- und Seelenleben (Cotta) Stuttgart \& Augsburg

Flemming, C. F. (1859) Pathologie und Therapie der Psychosen. Berlin

Freud, S. (1895) Über die Berichtigung, von der Neurasthenie einen bestimmten Symptomenkomplex als "Angstneurose » abzutrennen, in Studien Ausgabe, vol 6, Hysterie und Angst.

Freud, S. (1926) Hemmung, Symptom und Angst, Wien, 1926.

Gebsattel, V. E. Freiherr von (1951a) Die phobische Fehlhandlung, In: Grundzüge der Neurosenlehre in 2 Bänden, Urban \& Schwarzenberg, München Berlin Wien 1972, pp. $57-81$. 
Gebsattel, V. E. Freiherr von (1951b) Zur Psychopathologie der Phobien, In : Prolegomena einer medizinischen Anthropologie, Springer Verlag 1954, pp 47-74

Griesinger, W (1861) Die Pathologie und Therapie der psychischen Krankheiten, Stuttgart.

Hecker, E. (1893) Über larvirte und abortive Angstzustände bei Neurasthenie. Zentbl. Nervenheilk. 16, pp. 565-572.

Heinroth, J. C. A. (1818) Lehrbuch der Störungen des Seelenlebens oder der Seelenstörungen und ihrerBehandlung, Vol I \& II, Vogel, Leipzig

Heinroth, J. C. A. (1823) Lehrbuch der Seelengesundheit, Leipzig.

Ideler, K. W. (1835) Grundriss der Seelenheilkunde, Berlin.

Ideler, K. W. (1841), Biographien Geisteskranker in ihrer psychologischen Entwickelung. E.H. Schröder, Berlin.

Kraepelin, E. Psychiatrie. 8th Edition. 1915.

Krafft-Ebing R von. (1874) Die Melancholie, eine klinische Studie, Erlangen.

Loewenstein, L. (1904) Die psychischen Zwangserscheinungen; auf klinischer Grundlage dargestellet. Wiesbaden.

Reil J. C. H. (1803) Rhapsodien über die Anwendung der psychischen Curmethode auf Geisteszerrütungen. Halle.

Reil, JC (1812) Besondere Fieberlehre, Nervenkrankheiten. In : Über die Erkenntnis und Cur der Fieber, vol. 4. Wien.

Schneider K (1946), Klinische Psychopathologie, 14ème éd., Thieme, Stuttgart New York, 1992.

Wernicke, Carl Grundriss der Psychiatrie in klinischen Vorlesungen. Leipzig: G. Thieme 1900. 23ème Conférence.

Westphal, C. (1872) Die Agoraphobie, eine neuropathische Erscheinung, Archiv für Psychiatrie und Nervenkrankheiten, vol III, Berlin. 


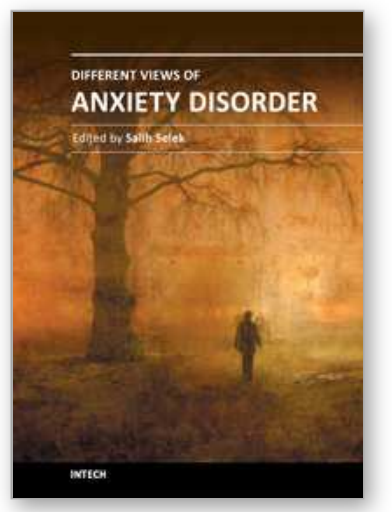

\author{
Different Views of Anxiety Disorders \\ Edited by Dr. Salih Selek
}

ISBN 978-953-307-560-0

Hard cover, 370 pages

Publisher InTech

Published online 12, September, 2011

Published in print edition September, 2011

Anxiety, whether an illness or emotion, is a term with historical roots even in the Bible, but it was not popular until the modern age. Today, we can group, diagnose and treat several anxiety disorders to an extent, but the assessment of symptoms and severity, dealing with resistant conditions, new treatment modalities and specific patient population, such as children, are still the challenging aspects of anxiety disorders. This book intends to present anxiety disorders from a different view and discuss a wide variety of topics in anxiety from a multidimensional approach. This Open Access book addresses not only psychiatrists but also a broad range of specialists, including psychologists, neuroscientists and other mental health professionals.

\title{
How to reference
}

In order to correctly reference this scholarly work, feel free to copy and paste the following:

Marc Géraud (2011). Anxiety and Its Nosographic and Psychopathologic Place in German Psychiatry: A Historical Perspective, Different Views of Anxiety Disorders, Dr. Salih Selek (Ed.), ISBN: 978-953-307-560-0, InTech, Available from: http://www.intechopen.com/books/different-views-of-anxiety-disorders/anxiety-and-itsnosographic-and-psychopathologic-place-in-german-psychiatry-a-historical-perspective

\section{INTECH}

open science | open minds

\section{InTech Europe}

University Campus STeP Ri Slavka Krautzeka 83/A 51000 Rijeka, Croatia

Phone: +385 (51) 770447

Fax: +385 (51) 686166 www.intechopen.com

\section{InTech China}

Unit 405, Office Block, Hotel Equatorial Shanghai No.65, Yan An Road (West), Shanghai, 200040, China 中国上海市延安西路65号上海国际贵都大饭店办公楼 405 单元 Phone: +86-21-62489820

Fax: $+86-21-62489821$ 
(C) 2011 The Author(s). Licensee IntechOpen. This chapter is distributed under the terms of the Creative Commons Attribution-NonCommercialShareAlike-3.0 License, which permits use, distribution and reproduction for non-commercial purposes, provided the original is properly cited and derivative works building on this content are distributed under the same license. 